\title{
EL PENSAMIENTO MITOLÓGICO COMO SISTEMA COGNITIVO DE LAS ETNOCIENCIAS
}

Jorge Trujillo, Juan Cadena

Universidad Central del Ecuador

Recibido: 23 - octubre -2015, aprobado: 24 - noviembre - 2015

\section{Resumen}

El tratamiento de diversos conocimientos geométricos, algebraicos o simplemente aritméticos de las sociedades a las que se consideran ágrafas, ha dejado de ser una subdisciplina nacida de la antropología e inserta en las matemáticas y pretende convertirse en una nueva ciencia. Dos inquietudes suscitan esta pretensión: en primer lugar, si el episteme o sistema cognitivo de las etnomatemáticas encuentra soporte válido en el pensamiento mitológico que figura como antecedente y, a la vez, fundamento de las etnociencias; y, en segundo lugar, si las etnomatemáticas admiten una teoría, y si ésta, de ser factible, reuniría los requisitos de una teoría autónoma. Los autores analizan estas inquietudes asumiendo como referente la literatura producida por etnólogos, filósofos y etnomatemáticos que han abordado, desde diversas perspectivas, temas involucrados en este artículo.

Palabras clave: ciencias matemáticas, epistemología, etnociencias, etnomatemáticas, lógica de los mitos, mitológicas, pensamiento mítico.

\begin{abstract}
The treatment of different types of geometric, algebraic or simply arithmetic knowledge that belong to societies considered without writing, have stopped being a sub discipline born within anthropology and inserted into mathematics, and now is endeavoring to become a new kind of science. This claim raises two main questions: Firstly, whether ethno mathematics' cognitive system $(\varepsilon \pi \iota \sigma \tau \varepsilon \mu \varepsilon)$ finds a valid support in mythological thought which figures as both, ethno mathematics' starting point and the basis of the ethno sciences. Secondly, whether ethno mathematics can be recognized as a specific theory; and, if this recognition is feasible, whether it will meet the conditions for it to be an autonomous theory. The authors analyze these concerns assuming as reference the literature written by ethnologists, philosophers and ethno-mathematicians who have dealt with the issues discussed in this paper from different points of view.
\end{abstract}

Keywords: mathematical sciences, epistemology, ethno sciences, mythological, mythologies, mythical thought. 
"El espacio puede producir nuevos mundos" John Milton, El paraíso perdido, 1667

\section{¿Qué es la etnomatemática?}

El punto de partida de nuestra reflexión es esta pregunta, sencilla en apariencia, aunque, a medida que nos adentramos y comprendemos sus implicaciones, se muestra no sólo como una ruta iniciada hace pocos años por algunos investigadores empeñados en encontrar métodos innovadores para la enseñanza de las matemáticas en contextos pluriculturales, sino, además, como una expectativa de valoración de los saberes de los pueblos periféricos a los centros civilizatorios contemporáneos, en particular, de los pueblos indígenas de los países suramericanos.

Estos temas son críticos en sociedades cuya pluriculturalidad se basa en migraciones recientes; lo son aún más en las que el balance histórico pluricultural, a pesar de los discursos sobre la alteridad, expresa inevitables relaciones sociales y culturales de dominio y subordinación que, en otros ámbitos, son percibidas como hegemonía de la ciencia universal, en cuanto forma única de conocimiento, sobre un conjunto de saberes antiguos, abatidos -si no excluidos-, a los que se consideró y considera expresión de ignorancia o deleznables formas de pensamiento precientífico o, peor, prelógico.

En años recientes, en la mayoría de los informes de investigaciones inspiradas en la búsqueda de saberes en diversos contextos históricos y culturales es posible detectar manifestaciones de optimismo. En la mayoría de los casos, por los hallazgos -sin duda notables- de sistemas numéricos quinales, decimales o vigesimales y apreciables construcciones geométricas o lógicas; en otros, por aplicaciones igual, notables- a mediciones de periodicidades (calendarios), o a registros estadísticos. Para esos investigadores, estos hallazgos tienen la virtud de ser utilizados como medios eficaces para la enseñanza y aprendizaje de las matemáticas.

Para otros, es suficiente la constatación que en las culturas americanas hubo condiciones culturales que han facilitado la adopción de la tecnologías de las computadoras (por ejemplo, códigos simbólicos binarios). Y no faltan quienes sostienen que esos saberes, comparables con las operaciones con los números p-ádicos o la geometría fractal, sintetizan resultados sorprendentes en aplicaciones como los sistemas agronómicos o el manejo de recursos en formaciones boscosas. A tal punto llega este entusiasmo que tampoco están ausentes quienes anuncian verdaderas revoluciones cognitivas o, cuando menos, celebran la asombrosa actualidad de saberes de data antigua sobre la base de tales descubrimientos.

Lo cierto es que, al término de una breve trayectoria inicial (1985-2015), algunos de los más notables resultados de las investigaciones en etnomatemáticas plantean inevitables interrogantes que parece imprescindible asumirlas como punto de partida de este artículo. Una de éstas puede ser formulada de la manera siguiente: ¿reflejan las diversas expresiones de las culturas americanas apreciables avances matemáticos que han permanecido ignorados? 
Con respecto al tema central, antes de abordar los acápites expositivos, parece oportuno aportar con algunas aclaraciones que consideramos imprescindibles. ¿Qué son las etnomatemáticas y en qué se diferencian de las ciencias matemáticas? Las ciencias y las etnociencias son invenciones históricas. De las primeras podemos asumir que nacieron con la filosofía, en la Grecia antigua, y no fueron formalizadas como tales sino a partir de los siglos XVII y XVIII. Las etnociencias constituyen un intento reciente, visible desde finales del siglo anterior, para formalizar los saberes de las sociedades no civilizadas reconociendo su estatuto, ya adquirido, de conocimientos sistemáticos. Este intento lo condujeron antropólogos que en sus investigaciones fueron sorprendidos por sus alcances. La denominación etnociencias es, a la vez, un reconocimiento de similitudes y diferencias. Similitudes por cuanto, en los dos casos, se trata de conocimientos sistemáticos, sobre todo en las ciencias empíricas, botánica y zoología, en tanto que las diferencias están basadas en el empleo de categorías descriptivas distintas.

El caso de las matemáticas es distinto. En todas las versiones se trata de construcciones lógicas. Las que conocemos como ciencias matemáticas ostentan avances espectaculares al término de una trayectoria que comenzó con las civilizaciones que surgieron en Mesopotamia, avanzaron con la geometría que aportaron los egipcios en base de las mediciones de las crecentadas del Nilo y se enriquecieron con los aportes de los sabios griegos, antes de pasar al escenario europeo por la mediación de los árabes, con nuevos aportes que éstos asimilaron de los persas, hindúes y chinos. De manera que, si esta breve reseña es válida, podemos afirmar que las ciencias matemáticas son, desde sus orígenes, conocimientos de distinta procedencia cultural que fueron sistematizados en la tradición greco latina hacia cuyo cauce convergieron en épocas ulteriores diversos conocimientos alcanzados por otras civilizaciones.

En este punto, la pregunta pertinente es la siguiente: ¿hubo aportes de las civilizaciones americanas? Aludiendo, por ejemplo, al contexto histórico en el que ocurrió el descubrimiento del continente, el hecho que los europeos, en ese momento, no hayan valorado el notable desarrollo de las ciencias americanas, más que una actitud soberbia, revelaría la falta de referentes de las ciencias de su época, en particular las matemáticas, que permitieran comprender esos alcances y realizaciones. Dominado el pensamiento filosófico europeo por la teología, podemos incluso asumir que fueron los motivos religiosos los que velaron los conocimientos plasmados en esos diseños arquitectónicos o en los sistemas de riego o en la agricultura o, incluso, en las formas sociales y políticas que posibilitaron el surgimiento de tales invenciones.

De esta atadura teológica escolástica no se liberaría a la filosofía sino hacia fines del s. XVIII, por causa de la búsqueda de nuevos paradigmas cognitivos. $Y$, en el caso de las ciencias, respecto de la filosofía, no ocurrió sino cuando al término del inicial proceso de formalización, llegaron hasta el s. XIX con nuevas propuestas epistemológicas. En el esquema aristotélico, y luego escolástico, las ciencias formaban parte del sistema especulativo del pensamiento filosófico. $\mathrm{Y}$ hasta cuando las ciencias adquirieron su carácter formal, fueron -y en algunos casos son todavía-, consideradas como sistemas derivados de reflexiones filosó- 
ficas. Y puesto que el diálogo entre la filosofía y las ciencias no ha cesado, parece oportuno iniciar este artículo haciendo una referencia, aunque breve, a ese vínculo antecedente en el primer acápite de este artículo.

El tema es imprescindible si se considera que la crisis de la filosofía y de las ciencias constituye el contexto contemporáneo en el que se despliega la tendencia, antes aludida, a relativizar el carácter universal de las ciencias, arguyendo su inevitable vínculo con los ejes de la civilización occidental y su alejamiento de otros sistemas cognitivos; de manera particular de las sociedades indígenas americanas. De manera que parece evidente la necesidad de adoptar un horizonte común en el que conocimientos y saberes, postulados como etnociencias, sean instituidos, por igual, como referentes de la era del conocimiento.

Este esfuerzo por valorar los saberes de las culturas indígenas en ocasiones es más una constatación empírica que una reflexión teórica sistemática dirigida a encontrar fundamentos sólidos para esa propuesta. El hecho cierto es que pocos de los cultores de las etnomatemáticas o, en general, de las etnociencias, han precisado los aspectos cognitivos que tal planteamiento requiere como condición sine qua non para ser postuladas como ciencias. Y, el otro hecho cierto es que, a la antropología hay que dirigir la mirada e inquirir acerca de los fundamentos de esas modalidades cognitivas.

Esta es una de las virtudes de las proposiciones de Lévi-Strauss (1908 - 2009) sobre las que sus comentaristas y críticos han puesto mayor énfasis. En el segundo acápite expondremos algunas referidas al pensamiento mitológico. Considera Lévi-Strauss que este pensamiento, al que denomina natural o mito-lógico, es producto de un desarrollo diverso al de la filosofía y las ciencias; pero no por esta razón es su antecedente o esbozo prelógico; o, peor aún, como planteó Lévy-Bruhl o sugirió Freud, un pensamiento de categoría inferior o subordinada. Cierto es que esta dimensión del pensamiento de las sociedades americanas ha sido el aporte de la antropología ${ }^{2}$, ciencia formalizada tardíamente, al igual que la lingüística; y, lo es también el hecho que, desde este mismo ámbito antropológico, es desde donde se ha mostrado que los saberes de esas sociedades constituyen paradigmas distintos de los que caracterizan a las ciencias convencionales, pero no por esta razón carentes de eficacia.

En el tercer acápite asumimos el tratamiento de las etnociencias y las etnomatemáticas con el estudio específico de los sistemas numéricos y las posibles construcciones matemáticas de algunas culturas americanas. Más allá de los planteamientos de Lévi-Strauss, el contexto americano muestra evidencias de un apreciable desarrollo cultural. No se trata de sociedades ágrafas -por toda la carga ideológica que conlleva el término- sino de sociedades que históricamente desarrollaron concentraciones urbanas, redes de intercambio y de comercio a larga distancia, navegación de cabotaje, notable producción de objetos cerámicos y explotaciones agrícolas con registros sorprendentes de biodiversidad. Todas estas expresiones culturales, algunas de ellas vigentes, no fueron posibles sino a partir

2 O, con mayor precisión, etnología o disciplina científica dedicada al estudio comparado de diversas expresiones culturales de las sociedades periféricas a los ejes civilizatorios. De manera que las etnociencias serían, en un sentido, las ciencias de estas sociedades. 
de saberes tanto empíricos, basados en los conocimientos del entorno, como lógicos, en particular, construcciones matemáticas.

En el cuarto acápite que corresponde a las conclusiones, retomamos el tema central del artículo; esto es, la breve reflexión, antes expuesta, y desarrollada en los acápites subsiguientes, sobre los aspectos epistemológicos de las etnociencias, incluida la etnomatemática, con una propuesta esbozada en el ámbito cognitivo que sugiere algunas ideas a los investigadores que enfrentan el reto de la búsqueda de coherencia a los conocimientos o saberes antiguos o contemporáneos de las sociedades de la periferia de las civilizaciones contemporáneas.

\section{Crisis de la Filosofía y de las Ciencias}

"No es un accidente que el surgimiento de la física newtoniana en el siglo XV II, y el de la relatividad y de la mecánica cuántica en el XX, hayan sido precedidos y acompañados por análisis filosóficos fundamentales de su tradición contemporánea de investigación".

Thomas Kuhn. La estructura de las revoluciones científicas.

Transcurridos unos 9.600 años desde la revolución neolítica en la Mesopotamia, y 2.400 años desde la invención de la rueda, los metales y la escritura, esto es, hacia el 400 a.C., en la cultura griega, legataria de esas tradiciones, se produjo una radical escisión entre los mitos y el pensamiento filosófico: la monumental compilación de mitología de Hesíodo (s. VIII a.C.) y los contemporáneos poemas épicos de Homero fueron reprobados por una ralea de filósofos que los calificó como narraciones fantasiosas. En su lugar postularon como opción válida las construcciones lógicas del pensamiento abstracto, a cuyos resultados denominaron sabiduría, sofía, a los cultores de esta forma de pensamiento, amantes de la sabiduría, o filósofos y, a su práctica, filosofía.

Se basaron estas construcciones lógicas en la convicción de que la realidad sensible es pura apariencia y que más allá de lo físico hay una realidad, la metafísica, a la que el hombre debe dedicar sus reflexiones para desentrañar los misterios de su existencia. Uno de sus máximos exponentes, Platón (428-347 a.C.), entre sus enseñanzas en la Academia o Escuela Peripatética, dejaría para la posteridad la imagen que ilustra este paradigma: la realidad sensible se reduce a espectros, fantasías o sombras que, proyectadas al fondo de una caverna, crean en los hombres la ilusión de la verdad, puesto que éstas no son sino formas degradadas de las ideas que perviven en su mundo, perfecto incorruptible y eterno.

Al desenvolvimiento de este axioma del pensamiento griego se atribuye el origen de las ciencias que, siguiendo el modelo aristotélico, son construcciones lógicas logradas a partir de formulaciones conceptuales que la razón o el pensamiento deducen de la Verdad Absoluta del Mundo de las Ideas y las adecúan a los epifenómenos observables en la realidad sensible. Aunque en el mismo escenario surgieron planteamientos que postularon la primacía de la realidad sensible no tuvieron la misma resonancia histórica que logró el idealismo platónico, aunque contribuyeron a establecer el paradigma cognitivo que consagra en ciertas épocas y escuelas de pensamiento la primacía de la razón y, en otras, la de los sentidos. De allí en adelante, en ulteriores evoluciones en el escenario europeo, la filosofía y las ciencias se han desenvuelto en base de la lógica conceptual y en medio de 
las opciones del idealismo y materialismo, formulaciones extremas del paradigma filosófico griego legado a Occidente.

Hacia el s. XIX, este paradigma culminó su trayectoria en la formulación idealista de Hegel (1770-1831), seguida de la versión materialista de Marx (18181883). De esta manera, en el contexto de la filosofía alemana, en medio de la carencia de nuevos planteamientos, según el criterio de filósofos contemporáneos, se hizo patente el agotamiento de estas antinomias del pensamiento griego como expresión de la decadencia del potencial hermenéutico de la filosofía conceptual y metafísica.

Fue éste el punto de partida para propuestas innovadoras que abrieron nuevos derroteros epistemológicos y ampliaron el horizonte de la filosofía, ya no como metafísica, sino como ciencia. La propuesta más notoria fue la fenomenología postulada por Husserl (1859-1938), como una respuesta a la crisis, puesto que, según él, requería de bases epistemológicas sólidas para ser postulada como ciencia. De esta escuela surgieron algunos pensadores que marcaron el desarrollo de la nueva filosofía a partir de esta innovadora propuesta epistemológica ${ }^{3}$. Uno de éstos, Heidegger (1889-1976), uno de sus discípulos, se convirtió en la figura crucial de la filosofía existencialista.

Sin embargo, los críticos de la filosofía metafísica no encontraron en estas iniciativas sino réplicas del paradigma del que renegaban. De esta manera, tanto la fenomenología husserliana como la bergsoniana así como el existencialismo en sus diferentes versiones fueron rápidamente desechados puesto que consideraron que sus propuestas, concebidas como renovados intentos por replantear la tradicional metafísica no lograron sino replantear viejos esquemas para asignar roles al sujeto, bien como simple operador de las secuencias fenomenológicas, bien como portador pasivo del hecho de la existencia.

Pronto estas inquietudes, que se proyectaron como temas que inspiraron las filosofías de la crisis decimonónica, hallaron eco en el contexto de la filosofía inglesa que, al igual que algunos antiguos seguidores de la fenomenología, predicaban la rebelión contra la metafísica y el idealismo, al mismo tiempo que postulaban el radical viraje de la filosofía metafísica y conceptual hacia los planteamientos de la filosofía como ciencia. Nació así la filosofía del lenguaje. Los planteamientos de Alfred North Whitehead (1861-1947) y Bertrand Russell (1872-1970), publicados como Principia Mathemática ${ }^{4}$ conocieron años después otra versión, la del austríaco Ludwig Wittgenstein (1889-1951), discípulo de Russell, difundida en su Tractatus lógico philosophicus (Logisch-Philosophische Abhandlung, 1921) y un innovador replanteo en sus investigaciones filosóficas (Philosophische Untersuchungen, 1953).

Estos intentos no fueron los primeros. Siglos antes, Leibniz (1646-1716) imaginó esta posibilidad en base del método combinatorio, por él inventado, al tiempo que Baruch Spinosa (1632-1677) propuso un sistema filosófico basado en métodos matemáticos, y, algo más tarde, Boole (1815-1864) diseñó un sistema

3 Influenció el pensamiento de Sartre, Merleau Ponty y Ortega y Gasset.

4 1910-1913. Es conocida la afirmación de Whitehead, "Toda la filosofía occidental se reduce a una serie de notas escritas al margen de las páginas de Platón”. 
algebraico para servir de gramática y diccionario de un sistema lógico ${ }^{5}$. Boole en 1854 publicó su obra Una investigación de las leyes del pensamiento, sobre las cuales se fundan las teorías matemáticas de la lógica y de las probabilidades. Acerca del tema que nos interesa, explica su propuesta en los términos siguientes:

\begin{abstract}
El objeto del $[\ldots]$ tratado es investigar las leyes fundamentales de esas operaciones de la mente en cuya virtud se realiza el razonamiento; expresarlas en el lenguaje de un cálculo, y sobre ese fundamento establecer la ciencia de la lógica y construir su método; hacer de ese método la base de un método general para la aplicación de la teoría matemática de las probabilidades, y, finalmente, recoger de los diversos elementos de verdad que surgen en el curso de estas pesquisas algunas probables informaciones referentes a la naturaleza y constitución de la mente humana... (Boole: cit. por Bell: 502).
\end{abstract}

Hemos puesto énfasis en el tema de la lógica simbólica o lógica matemática por cuanto, según veremos a lo largo de la exposición del artículo, es un tema al que convergen, además de la filosofía, las ciencias en general (incluidas la lingüística y la antropología), y, lo que resulta más interesante, la lógica de los mitos.

Aunque la crisis de los paradigmas de las ciencias ocurrió hacia la misma época, no fue consecuencia de la crisis de la filosofía; fue el punto culminante de un largo itinerario que tuvo como remoto antecedente el abandono de las explicaciones escolásticas. Éstas estuvieron basadas en los postulados aristotélicos que los árabes difundieron en el Mediterráneo, desde el s. XII, a través de la escuela de traductores de Toledo y los aportes de sabios de Bizancio que huyeron de la invasión turca de los que fueron llevados a Europa por nobles y sacerdotes que participaron en las cruzadas ${ }^{6}$

Las ciencias alcanzaron su formulación formal a partir del s. XVII y XVIII. El entorno pre científico renacentista muestra, de todas maneras, algunos avances. La influencia de la antigua tesis ptolemaica sobre la esfericidad de la Tierra y la expansión de las rutas marítimas de comercio incidió en la sistematización del conocimiento astronómico que culminó en la formulación de la tesis heliocéntrica de Copérnico (1473-1543) y ulteriores planteamientos que impulsaron Tycho Brahe (1546-1601) y Kepler (1571-1630).

Los italianos desempeñaron roles protagónicos en el proceso de cimentación del desarrollo de las matemáticas. Guerrero (2004: 108 y ss.) menciona los aportes de Scipio Ferro (1465-1526), Nicolo Fontana (1500-1557) y Girólamo Cardano (150-1576). A éstos, según el mismo autor, se sumaron los del francés Vieta (1540-1603) y, sobre todo, del escocés Napier (1550-1576).

La posterior formalización de las ciencias fue un proceso que, en sus inicios, se fundamentó en la filosofía empirista de Bacon (1561-1626), continuada por Locke (1632-1704), y en el método deductivo de Descartes (1596-1650). Excepto Rousseau (1712-1778), ni ellos ni sus seguidores poco o nada encontraron de nota-

5 Aparte de otras invenciones sobre las magnitudes constantes y aportes para el desarrollo ulterior de la teoría de las probabilidades y de las matemáticas binarias.

6 Entre 1095 y 1270 fueron organizadas ocho cruzadas. Éstas se sumaron a las tres cruzadas que, años antes (1063-1085), formaron parte de la reconquista iniciada desde Bizancio y España. 
ble en las culturas americanas, pese al conocimiento relativamente avanzado de sus sociedades y cultura. Tampoco encontraron argumentos para valorizar las culturas americanas y de otros continentes quienes protagonizaron la posterior evolución de la Filosofía y las Ciencias en Europa a lo largo de los s. XVIII y XIX, aunque naturalistas de la talla de Bouganville, La Condamine, Chardin, Humboldt, Wallace y Darwin ya habían llamado la atención sobre las diferencias del entorno natural, las sorprendentes adaptaciones culturales y los admirables vestigios de ciudades y edificaciones monumentales en América, Oceanía, Persia y la India ${ }^{7}$.

En tanto las nuevas ciencias formalizaban su estatuto de conocimiento axiomático, por su parte, las ciencias naturales, de manera particular la biología, a partir de Darwin y Wallace, anclada sobre la indagación empírica, abrió nuevos horizontes en torno a la idea o proyecto de la historia natural, otorgando a la evolución humana la nueva categoría de temporalidad o historicidad que las tesis creacionistas habían negado para la naturaleza y la especie.

La crisis de los paradigmas cartesianos y newtonianos no se produjo sino años después, hacia finales del s. XIX e inicios del XX, cuando espectaculares avances de las investigaciones en las ciencias matemáticas ampliaron de manera inusitada los hasta entonces reducidos horizontes de sus construcciones lógicas. Entre otras, Guerrero (2004: 171 y ss.) menciona la teoría de los números transfinitos de Georg Cantor (1845-1918), la curva de Peano de Guissepe Peano (1858-1932), la lógica de la geometría de David Hilbert (1862-1943), la curva de Koch de Helge von Koch, el tapete de Sierpinski de Waclaw Sierpinski (1882-1969) y Gaston Julia (1893-1978), y la geometría fractal de Benoit Mandelbrot (1924-2010), avances que hicieron posible la formulación de la teoría de la relatividad de Albert Einstein (1879-1955) junto con la mecánica cuántica de Wiener Heisenberg (1901-1976), la geometría riemanniana de Berhard Riemann, (1826-1866), el cálculo tensorial de Ricci y Levi Civita y la teoría cuántica de Max Planck (1858-1947).

Otros avances, como la matemática binaria, como principio operativo de las computadoras de Claude Shannon (1916-2001) y los números p-ádicos de Kurt Hensel (1861-1941) fueron difundidos a lo largo del siglo pasado. Lo insólito de estos aportes no radica en su distanciamiento respecto de la geometría euclidiana, del espacio de representación cartesiana y de la visión mecánico corpuscular newtoniana sino en una concordancia sorprendente con el pensamiento natural que Lévi-Strauss, y, antes que él, James Georges Frazer y Marcel Mauss, habían encontrado en las sociedades tribales a las que dedicaron sus estudios.

No fue sino en pleno s. XX, a raíz de la crisis de la filosofía y de las ciencias occidentales y de los aportes de la etnografía, que los renovados planteamientos de las ciencias matemáticas permitieron el redescubrimiento del valor de las invenciones de otras culturas que coexistían con el desarrollo de la civilización industrial y urbana. Algunas fueron apreciadas como logros que no fueron percibidos sino a partir de la evolución reciente de las ciencias matemáticas, como la geometría fractal, los números pádicos y las matemáticas binarias. De hecho, ése fue el fundamento de la etnomatemática y, por supuesto, de las etnociencias.

7 Antes que todos, José de Acosta y Gregorio García. 
Sin embargo, el surgimiento inusitado de estas disciplinas suscitó la sospecha de que es posible que estemos atribuyendo a estas culturas conocimientos que nunca los poseyeron; o bien, caso contrario, que estamos ante saberes que sorprendentemente remontan sus orígenes a épocas anteriores a la expansión civilizatoria decimonónica, y que, de alguna manera, resultan convergentes con posteriores avances de la ciencias matemáticas.

Estas inusitadas concordancias entre los avances contemporáneos de las ciencias matemáticas y el pensamiento mito-lógico no fueron casuales. En cierto sentido, las ciencias sociales habían experimentado una crisis similar: la búsqueda de su formalización logró grandes avances con Sigmund Freud, Emile Durkheim y Marcel Mauss; pero sobre todo con la semiología propuesta por Ferdinand de Saussure; estos planteamientos inspiraron la propuesta estructuralista de Lévi-Strauss que parte de un nueva concepción de los alcances de la revolución neolítica, según se expone en el acápite siguiente.

\section{El pensamiento mitológico}

"El lenguaje es un ordenamiento eficaz de la enigmática abundancia del mundo"

Jorge Luis Borges

\subsection{La(s) revolución (es) neolítica (s)}

El hombre del neolítico marca la transición de la naturaleza a la cultura. No como un hecho histórico verificable sino, según Lévi-Strauss (1969: 35), como una distinción lógica, puesto que implica la adopción de reglas de intercambio matrimonial, y, en consecuencia, de las concepciones del parentesco consanguíneo y afín (1969: 41). Además, la revolución neolítica, con uno de sus principales aportes tecnoeconómicos, la agricultura, es asumida como el punto de partida de culturas y civilizaciones. Esta revolución tuvo lugar en el escenario mesopotámico donde se desarrollaron notables sociedades sedentarias. Aunque, recientes investigaciones arqueológicas proporcionan evidencias que permiten sostener que un similar evento ocurrió en Mesoamérica. Y no en un solo sitio sino, de manera simultánea, en varios entornos.

$Y$ es posible que otras hayan ocurrido en otros continentes. Nos interesa tan sólo enfatizar que a partir de estas revoluciones neolíticas fue posible el ulterior desarrollo de las culturas y civilizaciones en el planeta. A fin de comprender el desarrollo neolítico en el continente americano, por causa de la previa expansión de la especie humana que estas revoluciones suponen, es preciso explicar otros eventos que tuvieron que ver con este proceso. Se trata de las migraciones que poblaron el continente. La hipótesis a la que se ha prestado mayor atención es la que postula que se produjo en base de una o varias migraciones provenientes del continente asiático. Se fundamenta en el hecho que el Estrecho de Bering durante determinados períodos fue transitable debido a efectos de las glaciaciones que ocasionaron una considerable baja de los niveles oceánicos. 
El gráfico 1. (Marsh: 2002) permite apreciar para un lapso de 140.000 años, contados a partir del inicio de nuestra era, las variaciones de los niveles oceánicos causados por las glaciaciones y los períodos interglaciales. El último de estos periodos que ocurrió hace $+/-18.000$ años, ocasionó una baja considerable estimada en $+/-140$ metros.

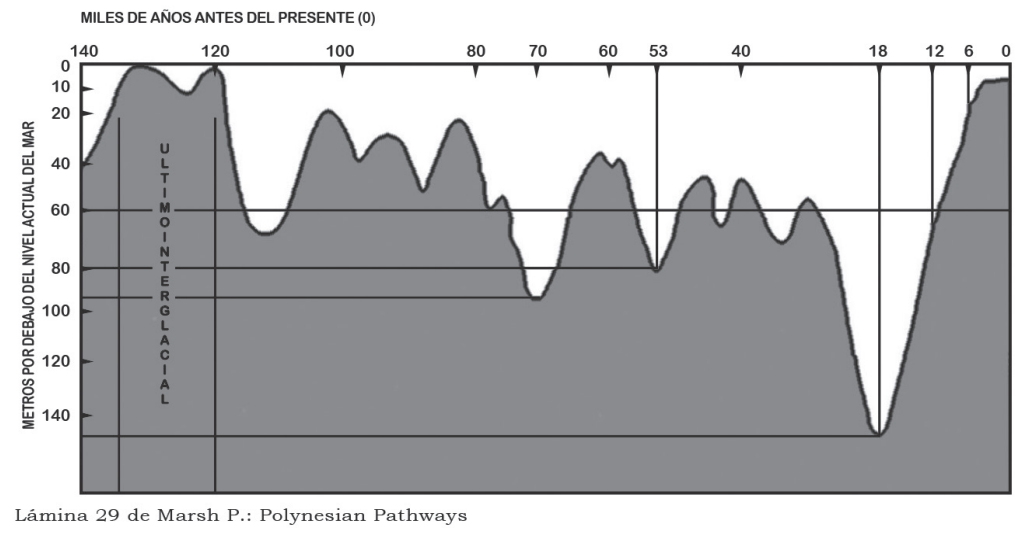

Gráfico 1. Variaciones de nivel de la superficie oceánica.

$\mathrm{El}$ argumento que concurre a demostrar la factibilidad de la hipótesis se basa en los resultados de las excavaciones arqueológicas. Éstas se han concentrado en el extremo noroeste del continente, aunque hay otras evidencias en otras latitudes. Puesto que se consideró que los migrantes eran cazadores del Paleolítico, esto es, anteriores a la invención y desarrollo de la agricultura, podemos establecer la cronología siguiente, incluyendo probables migraciones posteriores al Neolítico; esto es, ulteriores a la invención de la agricultura en Mesopotamia y Mesoamérica:

Tabla 1. Glaciaciones, nivel oceánico y evidencias arqueológicas.

\begin{tabular}{|l|l|l|}
\hline GLACIACIONES & NIVEL OCEÁNICO & EVIDENCIAS ARQUEOLÓGICAS \\
\hline$(+/-) 70.000$ & -92 metros & - \\
\hline$(+/-) 53.000$ & -80 & - \\
\hline$(+/-) 44.000$ & -62 & - \\
\hline$(+/-) 37.000$ & -70 & Noroeste continental (Alaska, Canadá) \\
\hline$(+/-) 18.000$ & -140 & América del Norte y Centro \\
\hline$(+/-) 12.000$ & -60 & Sur de Chile / Costas América del Sur \\
\hline$(+/-) 11.000$ & & Revolución Neolítica Mesopotamia \\
\hline$(+/-) 10.000$ & & Revolución Neolítica Mesoamérica \\
\hline$(+/-) 6.000$ & -15 & Evidencias de civilizaciones americanas \\
\hline
\end{tabular}

Fuente: Paul Marsh, gráfico anterior.

Elaboración: el autor

Guardando cierta coherencia con los datos registrados en la Tabla 1, podemos ampliar la hipótesis inicial proponiendo, como lo han hecho varios investigadores, no una oleada migratoria sino algunas, y en diversos momentos; de manera que es posible establecer una secuencia cronológica de la manera siguiente: 
Tabla 2

\begin{tabular}{|l|l|l|l|}
\hline \multicolumn{1}{|c|}{ MIGRACIONES } & MESOPOTAMIA & MESOAMÉRICA & PERIODO \\
\hline Anteriores a la RN & $(+/-) 40.000$ años & $(+/-) 37.000$ años & Paleolítico \\
\hline Coetáneas a las RN & $(+/-) 11.000$ años & $(+/-) 10.000$ años & Neolítico \\
\hline Migraciones posteriores & $(<) 10.000$ & $(+/-) 10.000$ años & Neolítico \\
\hline
\end{tabular}

\subsection{El alba de los mitos}

Para Claude Lévi-Strauss, cuyos planteamientos acerca del pensamiento mito-lógico son cruciales para comprender los orígenes de las etnomatemáticas, la(s) revolución(es) neolítica(s), además de la organización social, la adquisición de la agricultura y la domesticación de animales supuso el desarrollo de una forma particular de pensamiento que se expresó en las narraciones de mitos. Se trata de un lenguaje simbólico o de símbolos, construido por un sencillo procedimiento cognoscitivo que implica una secuencia de interacciones entre cultura y naturaleza. Al prolongado periodo de emergencia y espectacular desarrollo y difusión de esta forma particular de pensamiento la denominó El alba de los mitos (1981: 485 y ss.).

Si desde la perspectiva cognitiva analizamos este evento podemos aducir que se trata de la culminación de un proceso de conocimiento de los diversos entornos americanos ocupados por diversas sociedades: la sistematización de los conocimientos de las propiedades de las plantas y animales, de las periodicidades estacionales, de los ciclos de renovación de las formaciones boscosas permitió, entre otros factores, su registro en lenguajes simbólicos según las cualidades y formas reconocibles en la naturaleza. Este lenguaje y forma de pensamiento se desarrolló entre las poblaciones neolíticas. El surgimiento de la filosofía griega, y desde el punto de vista de las etnomatemáticas, el surgimiento de la geometría en Egipto, fueron los hitos que marcaron su diferenciación del pensamiento simbólico y el desarrollo de otra modalidad basada en conceptos abstractos y secuencias de construcciones lógicas, la que, siglos después, caracterizó al pensamiento filosófico en el contexto de la civilización occidental.

En el continente americano persistió el pensamiento natural o mito-lógico. Su desarrollo es perceptible en las civilizaciones meso y suramericanas, y con un despliegue notorio entre las sociedades que ocuparon espacios periféricos. El nivel civilizatorio alcanzado por las culturas americanas no implicó una ruptura con el pensamiento mito-lógico. Persiste en las literaturas o mitos de origen de los incas, mayas y mexicas lo mismo que en sus glifos y textos sagrados.

Lo curioso de este fabuloso ciclo de las narraciones de mitos es que no es sino un vasto conjunto de variantes de un mito originario, "El desnidador de aves". Los mitemas que marcan sus variantes, digamos, sintácticas son tan numerosas como las sociedades y lenguas de las que dejaron testimonio escrito los europeos, sobre todo misioneros, que arribaron al continente desde el s. XVI Las coincidencias estructurales sugieren una sola y misma matriz de la que se desprenden variantes que dan cuenta de entornos distintos, migraciones, intercambios comerciales, guerras; en fin, de diferentes procesos que, de una u otra manera pueden ser percibidos en tales variantes. 
Los textos de los mitos pueden explicar ciertos eventos que, sin embargo, no son recuentos históricos. Las sociedades americanas no admiten la historia, tal cual la definimos; excepto las civilizaciones de las que hay ciertos textos de versiones de memoria oral recopilados por algunos cronistas o los registros de hechos concretos de determinadas sociedades que constan en glifos. La historia como periodicidad de una sociedad no era posible en el contexto de secuencias generacionales que no eran sino iteraciones de un modelo que no admite sino pocas variantes.

\subsection{Epistemología estructural}

La fonología dio un paso decisivo cuando Ferdinand de Saussure (1857-1913) concibió a la lingüística como parte de una ciencia, la Semiología, a la que atribuyó por objeto el estudio de los signos. En términos lingüísticos, al asignar a un sonido la categoría de fonema, estableció que la combinación de sonidos, que opera a nivel inconsciente, forma las palabras y éstas, semantemas, el mensaje. De la misma manera, en los textos de los mitos es posible definir unidades que, articulándose entre sí, construyen una sintaxis o pensamiento o lógica de los mitos. Estas unidades, por su característica similar a la de los fonemas, Lévi-Strauss las denominó mitemas.

Este recurso, aparentemente metodológico, encuentra sustento teórico en el hecho que no sólo los fenómenos lingüísticos constituirían el objeto de la Semiología sino además otras expresiones de la cultura que pueden ser asimiladas a los signos. Esta opción es, en efecto, una consecuencia visible de la influencia de los planteamientos de Saussure. Según testimonia Lévi Strauss,

Nadie pondrá en duda que la antropología cuenta, en su campo propio, al menos con algunos de estos sistemas de signos, a los cuales se agregan muchos otros: lenguaje mítico, signos orales y gestuales que componen el ritual, reglas de matrimonio, sistemas de parentesco, leyes habituales, ciertas modalidades de los intercambios económicos. (1974: 26).

De esta manera, y desde el punto de vista de la Semiología, si el mitema es para la mitología lo que el fonema es para la expresión lingüística, su articulación, a nivel inconsciente, es la condición requerida para expresar su sentido ya que el texto narrativo de un mito o la representación de un rito o los sistemas de parentesco carecen de sentido por sí mismos. Esto es, en el caso del mito, un texto reenvía su mensaje a un contexto de mitemas donde operan un conjunto de transformaciones que otorgan sentido a distintos códigos culturales. Como manifiesta el autor (1974: 17), "el resultado final del estudio de las mito-lógicas es una sintaxis de la mitología sudamericana".

Por otra parte, a lo largo de sus investigaciones Lévi-Strauss descubrió que las estructuras de los mitos, en cuya construcción han intervenido diversos códigos culturales, revelan en su armadura verdaderos diseños geométricos cuyo análisis, conducen, de manera inevitable, al descubrimiento de un sistema "...de reglas lógicas de intercambio, susceptible de un tratamiento formal con ayuda de instrumentos matemáticos.”(1974: 15) 
Esta teoría de las transformaciones (si algún apelativo es posible) no fue tomada ni de los filósofos del lenguaje ni de los lingüistas, a pesar de la notoria influencia en el pensamiento de Lévi-Strauss de lingüistas de la talla de Saussure y Roman Jakobson (1896 - 1982). La teoría se inspiró en las ciencias naturales. El autor admite que fue la influencia de D'Arcy Wentworth Thompson (On growth and form: 1917), quien, analizando las mutaciones biológicas pudo explicar que se trata de transformaciones que consisten en diferencias visibles entre especies u órganos animales o vegetales al interior de un mismo género. Idea que remitió al autor a la obra de Alberto Durero (Tratado de la proporción del cuerpo bumano) y al pensamiento natural de Goethe. De esta manera, pudo establecer que la noción de transformación es inherente al análisis estructural siempre y cuando “...entre los elementos y las relaciones de varios conjuntos aparezcan lazos invariantes tales, como para que podamos pasar de un conjunto al otro por medio de una transformación" (1990:155-156).

Los aportes antes mencionados abrieron nuevas rutas para abordar el tratamiento de textos que hasta entonces fueron considerados vestigios, al igual que los mitos griegos, bien como relatos cosmogónicos o cosmológicos fragmentarios, por residuales, bien como expresión de formas de pensamiento pre-racional, al igual que otros textos narrativos como el cuento popular. Vladimir Propp (1895-1970) trabajaba sobre textos de los cuentos populares rusos. Ocurrió que, mientras Propp aplicaba un enfoque diacrónico, Lévi-Strauss abordaba el análisis de los mitos americanos desde una perspectiva sincrónica, distinta e innovadora.

El inevitable debate suscitado por estos investigadores mostró hechos inequívocos. En primer lugar, en cuanto al objeto de análisis: los cuentos populares, en general, son narraciones sujetas a un guión que se conserva invariante en las diversas versiones en las que únicamente cambian los personajes y los escenarios. No así los factores operacionales que suelen ser recursos u objetos mágicos, intervención de personajes que otorgan sentido a la trama y desembocan en finales más o menos felices. Por el contrario, los mitos carecen de argumento; son narraciones en las que no hay una estructura común y, aunque los factores operacionales de las transformaciones son similares a las de los cuentos, nunca desembocan en tramas reconocibles como en el caso de los cuentos.

En segundo lugar, Propp definió su método de análisis basado en el hecho que los cuentos populares pueden ser analizados diacrónicamente, puesto que son versiones cuyos orígenes pueden ser rastreados en imágenes simbólicas que expresan formas antiguas de organización social o política que precedieron al surgimiento de las civilizaciones. Lévi-Strauss difícilmente concuerda con este planteamiento puesto que (según veremos más adelante), las expresiones simbólicas del mito no son diacrónicas, en el sentido cronológico y lógico, sino que constituyen una forma de pensamiento presente incluso en los textos de mitos que perviven en los contextos civilizatorios, a veces bajo formas rituales, a veces en algunas expresiones literarias, como las novelas de folletín, y en la música.

$\mathrm{Y}$, en tercer lugar, mientras Propp encuentra en los cuentos populares rusos material para reflexionar acerca de la evolución de la narrativa oral, Lévi-Strauss 
se muestra más preocupado por encontrar una estructura sintáctica de los mitos que permita, a la vez, desentrañar los nexos de continuidad y transformaciones simbólicas y los aspectos de funcionamiento del pensamiento mito-lógico; esto es, alternativo al abstracto y conceptual.

Este célebre debate entre Propp y Lévi-Strauss puso en evidencia un aspecto hasta entonces poco conocido de los planteamientos del estructuralismo. Esto es, el atribuir al pensamiento mito-lógico un estatuto autónomo respecto del pensamiento filosófico y científico occidental. No sólo autónomo; puesto que el lenguaje simbólico y sus reglas operacionales inconscientes permean diversas expresiones culturales que podemos atribuir a la civilización.

Lo antes expuesto nos conduce a plantear la pregunta siguiente: ¿Es filosófico el pensamiento natural o mito-lógico? Para responder a esta pregunta conviene volver sobre lo dicho acerca de la crisis de la filosofía en los párrafos iniciales de este artículo. La ruptura con la tradición metafísica, concebida como lógica simbólica por Leibniz, Spinosa y Boole, y llevada a cabo por Russell, Whitehead y Wittgenstein, y la nula incidencia del pensamiento existencialista y de las propuestas de la fenomenología, conducen directamente a comprender la magnitud del planteamiento de Lévi-Strauss. Si la filosofía ha perdido su anclaje metafísico y se ha convertido en una filosofía del lenguaje; y si el lenguaje, a partir de la semiología de Saussure es más que el lenguaje natural, es lenguaje simbólico, parece obvio que se ha producido una silenciosa e inusitada innovación en el ámbito de las ciencias: "El ámbito de los estudios estructurales [incluiría] cuatro familias de ocupantes mayores que son los entes matemáticos, las lenguas naturales, las obras musicales y los mitos" (HN: 578).

Como es posible apreciar, estamos ante una nueva propuesta que define las categorías a las que se aplica el método estructural, de manera preferente, a causa de su afinidad. Esta tetralogía interrelacionada adquiere sentido como pares de oposiciones. Así, las estructuras de los entes matemáticos son puras y exentas de toda referencia que no sea la estricta lógica ${ }^{8}$. Las estructuras de la lengua son opuestas y están encarnadas y se originan de su intersección del sonido y el sentido. Las estructuras de la música, desligadas del sentido, se adhieren al sonido; no así en el caso de las estructuras mitológicas que, desligadas del sonido, se adhieren al sentido (1971: 578).

En este punto, podemos insistir sobre la pregunta inicial: ¿qué expresan los mitos si son postulados como pensamiento natural? Ciertamente nada acerca del mundo, la naturaleza de lo real, el origen del hombre o su destino, como lo hizo la filosofía;

[Únicamente] “... nos enseñan acerca de las sociedades de las que provienen, ayudan a comprender su funcionamiento, aclaran la razón de ser de ciertas creencias, costumbres e instituciones... y, sobre todo, permiten intuir ciertas formas de operar del espíritu humano, constantes a lo largo de siglos y ampliamente extendidas... (1981: 571).

8 Nótese la rigurosa similitud de este planteamiento con las proposiciones de Wittgenstein, Tractatus: " 0.2 La matemática es un método lógico. 6.21 Las proposiciones matemáticas no expresan ningún pensamiento." Tractatus Logico-Philosophicus (1921). 
¿De qué manera inicia Lévi-Strauss su itinerario que lo conduce al encuentro de la lógica de los mitos? En sus orígenes, el pensamiento mitológico surge del intento por mostrar cómo las categorías empíricas definidas por los contextos etnográficos pueden servir de instrumentos conceptuales para derivar nociones abstractas y construcciones o proposiciones lógicas (1964: 9). Este intento -que es un mega proyecto por el vasto universo seleccionado- define como ámbito de investigación el continente americano, asumiendo, como lo hace el autor, que su poblamiento histórico se originó de sucesivas migraciones desde el continente asiático que se habrían producido gracias a que los movimientos glaciares dejaron abierto el pasaje de Behring hace 53.000 años, y luego, nueva y secuencialmente, hace 42.000, 37.000, 18.000, 12.000 y 6.000 años. Durante este lapso, en el escenario de la Mesopotamia, mientras los sumerios inauguraban la revolución neolítica hacia el 12.000 a.C. en base a la domesticación de animales y la agricultura de cereales, en el continente americano, según muestran las dataciones de C14, en similares condiciones se habría producido una revolución (o varias) de similar magnitud (1971: 543-546).

En este contexto, Lévi-Strauss postula que estas poblaciones, de una u otra manera se mantuvieron en contacto, teniendo como referentes algunos centros civilizatorios, de los cuales, es posible que los principales hayan sido los de Mesoamérica (mayas y aztecas) y los Andes (incas). Interacciones como las guerras, alianzas e intercambios permitieron la consolidación de un amplio espectro de diversidades culturales en sus contornos, lo que constituyó un soporte sólido en torno al cual los mitos pudieron anclarse como testimonios no materiales de esos procesos.

El resultado es una mega construcción o una armazón sintáctica susceptible de lecturas secuenciales. En primer lugar, los itinerarios de las migraciones de las tribus que poblaron el continente Americano, objetivo principal de la indagación, cuyos resultados se sintetizan en los cuatro volúmenes de la serie Mitológicas ${ }^{9}$. En esencia, el descubrimiento de similitudes de ciertas secuencias de mitemas encontradas tanto en las tribus que ocuparon el segmento norte del continente como en las que ocuparon y ocupan la cuenca amazónica. Tales itinerarios son simplemente trazos posibles que la arqueología o la glotocronología, en algún momento, reconstruirán con la exactitud deseable, así como, sobre todo la arqueología, ha aportado con fechas y secuencias probables para describir este vasto desplazamiento en diversos sentidos.

En segundo lugar, la monumental reconstrucción, que incorpora a civilizaciones como el caso de los mayas, señala, de manera inequívoca, que los textos de los numerosos mitos que ha sido posible recopilar y de los que Lévi-Strauss utiliza aproximadamente un millar, son expresiones de un proceso que muestra el alcance de una revolución neolítica que transcurrió en un escenario distante y diverso del de oriente medio.

Los análisis de mitos americanos de la serie Mitológicas plantean, en tercer lugar, una renovada lectura de la diversidad de entornos y recursos tecnoeconó-

$9 \quad$ Publicados entre 1964 y 1971, Le cru et le cuit (1964), Du miel aux cendres (1967), L'origine des manières de table (1968), L'bomme nu (1971) 
micos que acreditan no sólo que tuvo lugar la revolución neolítica sino que ésta desembocó en una sorprendente diversidad cultural y sus transformaciones. De esta manera los mitos, y su variante teatralizada, lo ritos, se convierten en los ejes referenciales de una construcción insospechada de variantes de estructuras parentales, representaciones de la flora y fauna en relación con las periodicidades estacionales y de los ciclos temporales en referencia a posiciones planetarias y las constelaciones.

La obra de Lévi-Strauss, referida a los cuatro volúmenes de la serie Mythologiques, constituye el coronamiento de un esfuerzo que desde años atrás habían desplegado Frazer con The golden bough (1923-1926), Vladimir Propp con el análisis del cuento ruso e incluso las obras decimonónicas de los hermanos Grimm, Jakob (1785-1863) y Wilhelm (1786-1859) Cuentos infantiles y del hogar y Leyendas alemanas que son compilaciones de los cuentos populares germánicos.

¿En qué consiste el pensamiento mítico? En La pensée samvage (1962), Lévi-Strauss lo postula como un lenguaje simbólico. A diferencia del lenguaje corriente, en el que los signos son fonemas que articulan proposiciones, el autor propone que en el lenguaje de los mitos los signos son mitemas que, en conjunto, forman estructuras. De manera que, estas construcciones lógicas que tienen como referente la realidad sensible forman, a su vez, una filosofía del lenguaje.

En este punto, cabe plantear la pregunta -como lo han hecho varios comentaristas de su obra- que suscita la conclusión de las reflexiones planteadas por el autor en los cuatro volúmenes de Mitológicas; esto es, que la mitología americana, a la que se suma la de otras latitudes, presenta por sí misma la construcción estructural o sintaxis de los mitos que presenta el autor como corolario de sus indagaciones o si se trata de una interpretación que ocurre en su mente. El autor expone su punto de vista citando a Saussure: la estructura semántica del mensaje vehiculado por el lenguaje es inconsciente, lo mismo que su decodificación. De la misma manera, los mitemas, organizados en mensajes basados en múltiples transformaciones, son mensajes cuya decodificación ocurre a nivel inconsciente.

El pensamiento mito-lógico o pensamiento natural se origina en categorías empíricas que se refieren tanto a las cualidades como a las formas. Estas cualidades y formas se presentan pareadas, a manera de una serie binaria. En cierto sentido, cada cultura da cuenta de su entorno y de sus costumbres en la forma cómo estas categorías son construidas. Lo inteligible, las construcciones lógicas a partir de lo sensible, permiten procesar esta información.

Según expone este autor en varias de sus obras, las poblaciones americanas no han seguido la tradición filosófica europea que se origina en la filosofía conceptual y en construcciones lógicas. Su pensamiento se expresa en los mitos, textos que se diferencian de la literatura (aunque, de alguna manera hayan sido el fundamento de ciertos géneros literarios) y de la filosofía en el sentido que ésta, desde sus orígenes en la antigua Grecia, marcó un distanciamiento de la mitología. De manera que la lógica de los mitos o mito-lógicas, son construcciones lógicas que, a diferencia de la tradición filosófica occidental, no se basan en conceptos sino en la percepción de las cualidades y formas de la realidad sensible y su simboliza- 
ción. El mito se constituye en un puente o vínculo entre la naturaleza y la cultura. Las cualidades y formas sensibles forman parte del discurso mítico. Determinan los procesos lógicos que consisten en construcciones geométricas (topológicas), aritméticas o algebraicas.

\title{
3. Los Etnosaberes
}

\author{
"Tu alma es el mundo entero" \\ Hermann Hesse, Siddharta.
}

\section{1. ¿Etnociencias?}

A la pregunta, ¿por qué el mundo es cómo es?, no es difícil encontrar la respuesta apropiada: es porque así lo conocemos. De hecho, esta es la respuesta posible a la pregunta planteada; de esta manera, se propuso integrar al observador al objeto observado; esto, en un procedimiento interactivo de laboratorio. Incluso, fuera del ámbito de un experimento, la respuesta posible es un principio aplicable a cualquier ejercicio cognitivo, puesto que la pregunta alude a las posibles interacciones que pueden ser reconocibles entre el sujeto y el objeto del conocimiento; esto es, entre el espacio físico, objeto del conocimiento, y el espacio gnoseológico en el que se sitúa el sujeto cognitivo y en el que éste se representa el espacio físico.

Esta proposición tiene varias implicaciones. Entre otras, permite asumir que, fuera de esta simultaneidad, el espacio físico acaso existe; $\mathrm{y}$, en tal caso, su existencia sería indiferente al hecho del conocimiento. Sin embargo, cuando decimos mundo aludimos a una unidad cosmológica que es el resultado de un acto cognitivo. La cosmología, en cuanto representación, expresa la existencia del espacio físico en el cognitivo.

En realidad la pregunta no requiere respuesta puesto que su misma formulación sugiere una respuesta o varias respuestas posibles. En cualquiera de los dos casos, en singular o plural, involucra la coexistencia de lo físico y lo cognitivo. Y, en plural -y para lo que interesa para el tema de ese artículo-, admite la coexistencia de lo físico con varias cosmologías, sin pretensiones de verdad absoluta; o, lo que es lo mismo, el predominio de la relatividad en el espacio cognitivo o, como plantea el autor del artículo Les deuxzéros mayas (s/f: 4), "l'espace cognitif est loin d'être homogène et isotrope." Este espacio en el que impera el relativismo cognitivo aparece como uno de los fundamentos de la ciencia y las etnociencias; $\mathrm{o}$, si se prefiere, en general, de las etnociencias.

Siempre para fines de este artículo, hay otras implicaciones que tienen que ver con una visión retrospectiva del espacio cognitivo. Al respecto, podemos postular la invención de varios paradigmas cosmológicos histórico - culturales, que pueden ser asignados a dos grandes categorías: por una parte, el paradigma que comprende las representaciones cosmológicas espaciales geo y heliocéntricas y, en segundo lugar, el que comprende las representaciones temporales. Las primeras fueron desarrolladas en el contexto de la tradición cristiana, las segundas, corresponden, entre otras, a las cosmologías hindú y maya que se basan en cálculos precisos y sincronizados de magnitudes siderales. Desde luego, no interesa en 
estas versiones las explicaciones posibles de espacio y movimiento sino, supuestos éstos como ilusorios o repetitivos, la escala del tiempo en la que ocurren.

En los dos casos, no sólo estuvieron involucrados motivos seculares o exclusivamente matemáticos; los argumentos religiosos tuvieron roles decisivos, aunque en sentidos contrapuestos. Las cosmologías judaica, romana, griega y egipcia, centradas en la comprensión de las dimensiones espaciales, fueron asimiladas por el cristianismo, en tanto que, en las religiones brahmánicas o budistas o de los mayas, por citar pocos ejemplos, lo fueron las cosmologías centradas en la comprensión de las dimensiones temporales.

¿De qué manera fue inventado el cero como factor que propiciaba las operaciones matemáticas que este sistema de medición implicaba? Se ha establecido que la geometría nació en Egipto por la necesidad de medir los espacios agrícolas, habilitados para tal propósito por el limo depositado en las terrazas aluviales por las crecentadas cíclicas del Nilo. Fue un proceso empírico en el que la noción de cero no tuvo razón de ser, lo mismo que entre las culturas mesopotámicas, dadas a los registros comerciales y entre los griegos, absorbidos por la geometría y las propiedades armónicas y místicas atribuidas a los números. Únicamente cobró pleno sentido en su posterior desarrollo, con Descartes; aunque antes los árabes lo introdujeron tras la conquista y colonización de la Europa Mediterránea, siendo originario de la India. En el sistema de coordenadas cartesianas, la escala fraccionaria desembocó en el concepto del cero como punto terminal de magnitudes, secuenciadas vertical u horizontalmente, y que tienen como referente los ejes de coordenadas con valor cero como factor operacional.

Distinto es el caso de la medición del tiempo. El tiempo absoluto es el que contiene el principio y el fin del cosmos. Y, a la vez, en su forma absoluta, la eternidad o edad de las deidades; o, en las cosmogonías, el tiempo transcurrido desde la creación del mundo o de los ciclos cósmicos iterativos o de trayectoria espiral. Y, en su forma relativa, los ciclos planetarios, solares, lunares y venusinos, los ciclos estacionales, la duración de la vida humana o las secuencias generacionales.

Según los vedas, compilados en los textos del Surya Sidhantay del Brihat Sathaka, libros antiguos de la India, lo que se refiere a lo infinitesimal numérico como medida de las periodicidades temporales proviene del ámbito religioso: el alma humana, aunque incorruptible, es expresión de "lo infinitamente pequeño" frente a la cuenta contraria que desemboca en "lo infinitamente grande" que es Brahma. Aunque se puede sospechar que "lo infinitamente pequeño" culmina en cero como resultante del fraccionamiento sucesivo de las unidades de tiempo ${ }^{10}$ no es lo que ocurre puesto que comprende un singular sistema de submúltiplos de un día como unidad referencial. En ellos se puede encontrar una escala infinitesimal: en esta escala no figura el cero como culminación de las fracciones decrecientes. Aunque, desde el punto de vista doctrinario, el Nirvana, en cuanto implica la aniquilación de los seres en el seno de la divinidad, puede ser interpretado como el instante cero que marca el término y, a la vez, el inicio de los ciclos del eterno retorno.

10 http://centrodeartigo.com/articulos-de-todos-los-temas/article_2666+8.html 
En todo caso, la idea de cero, expresada en el Nirvana, será un aporte al budismo y con esta innovación pasará a China y Japón. En la variante Zen del budismo el cero es representado como un círculo (enzo). Significa: "no nacimiento, no muerte". Podríamos interpretar como una explicación escueta del eterno retorno. Pero, a la vez - dicen los maestros-, la esencia de este círculo es la expresión del sunyata, que es, "nada superfluo, nada falta". (Eido Tai Shimano \& Kogetsu Tani Roshi: 1990: 17). Esta expresión ya no sugiere un aforismo sobre el eterno retorno sino un concepto del cero como terminación o solución. Podríamos preguntarnos si, por ejemplo, se trata de cálculos de base decimal, en los que el cero es la solución terminal invariable, algo así como una cantidad mística, el símbolo platónico de la perfección, del ser parmenidiano, o del Dios en el Medioevo, o si, por el contario, alude al estado de la perfecta contemplación existencial budista ${ }^{11}$.

De cualquier manera que sea posible interpretar éstos y otros textos, sus construcciones cosmológicas que sustentaron sus discursos religiosos fueron posibles por el uso del cero como factor operacional que permite concebir los dos extremos existenciales: en el espacio, en el tiempo o respecto de la magnitud de los seres materiales, en un extremo, e inmateriales, en el otro. Puesto que, de esta manera, es posible concebir una explicación bastante satisfactoria desde la perspectiva de un orden cósmico que, ciertamente, dejaba sin solución el tema de la medición de los objetos ilusorios del mundo material.

En el mismo ámbito cosmológico que, según hemos visto, figura inmerso en los ámbitos de los textos religiosos, adquiere el cero otras connotaciones. Por ejemplo, en el modelo temporal maya es el factor que permitió fijar la cuenta larga y actuó como factor operacional del sistema numérico vigesimal. En el primer caso, como factor ordinal: el día anterior al registro del "primer día". Este hecho debió ser evidente para los sacerdotes (Akin Maio Ahau Can Mai) que idearon la creación del mundo basados en la convicción de que la escritura, en los glifos o en los libros (anahté) era, a su manera, una creación del mundo en la que intervenían sus deidades y de la que fueron testigos los sacerdotes, inventores del tiempo.

La invención del calendario Maya que se estima que ocurrió entre el 6 de agosto de 613 a.C. y el 22 de diciembre de 580 a.C., permitió registrar la sucesión de los imperios Maya por un lapso total de 2148 años $^{12}$. La cuenta larga supone que hay un primer día en el que arranca la cuenta. Digamos el 6 de agosto de 613 a.C. ¿Debemos asumir que el día anterior, el 5 de agosto, es el día cero? Es lo que sugiere la cuenta larga de otras tradiciones religiosas que asumen el día inicial de la cuenta como el primer día de la creación. El día anterior, lo mismo que los que le antecedieron son cuenta cero.

Varias religiones fueron legitimadas como ámbitos en los que se inventó el tiempo de la creación y, como complemento, el de su destrucción. Los antiguos hindúes definían la edad del Universo como una noche del sueño cósmico de Bra-

11 El aforismo del budismo zen enuncia que la realidad creada por la mente de Buda es apariencia destinada a desaparecer, así como la mente de Buda, e incluso el mismo Buda.

12 La contabilidad Maya es algo mayor, puesto que atribuye a la cuenta larga 5.131 años, contados hasta el año 2015. 
hma que duraba 4.320 años terrestres. Shiva, señor de la danza cósmica cuidaba del sueño de Brahma. Si Brahma despierta, acabaría el Universo ${ }^{13}$.

Lo que interesa de las cuentas largas es que permiten deducir, con cierta seguridad, el periodo en el que fue inventado el sistema de contabilidad que, a la vez que marca el tiempo transcurrido, revela concepciones lineales, circulares o espirales del transcurso del tiempo. En todo caso, materia para las disquisiciones filosóficas; e incluso para las matemáticas o etnomatemáticas, si se considera que los esfuerzos por medir el tiempo implican profundas reflexiones acerca del cero como punto de partida y punto de arribo de la creación de los dioses así como el modelo escalar del tiempo y sus implicaciones geométricas. Esto es, la nada antes del comienzo, el despliegue del tiempo -más que del espacio- como definición del cosmos y la culminación de toda creación al final de los ciclos temporales.

Para ilustrar esta curiosa aplicación de las matemáticas, o etnomatemáticas, a las cosmovisiones religiosas hemos sistematizado en la Tabla 3 una muestra de las cuentas largas cristiana, judaica, maya, musulmana y brahmánica:

Tabla 3: Cuentas largas según cálculos religiosos

\begin{tabular}{|c|c|c|c|}
\hline AÑo & TRADICIÓN & DESDE & COMENTARIOS \\
\hline 2.015 & Era cristiana & Nacimiento de Cristo & Calendario gregoriano. \\
\hline \multirow[t]{2}{*}{6.019} & \multirow[t]{2}{*}{ Era cristiana } & \multirow[t]{2}{*}{4.004 a. C. } & 139 generaciones anteriores a \\
\hline & & & Nabucodonosor (+/- 562 a. C.) \\
\hline \multirow[t]{2}{*}{5.779} & \multirow[t]{2}{*}{ Era judía } & \multirow[t]{2}{*}{ Creación del mundo } & Hasta el nacimiento de Cristo \\
\hline & & & transcurrieron 3.764 años. \\
\hline 5.131 & Era maya & Inicio de la cuenta larga & 3.116 años a. C. \\
\hline \multirow[t]{2}{*}{1.396} & Era & \multirow[t]{2}{*}{ Hégira } & Desde la huida de Mahoma de la \\
\hline & musulmana & & Meca. \\
\hline \multirow[t]{2}{*}{5.000} & Era & Kali-yuga (432.000 & 5.000 años transcurridos de la \\
\hline & brahmánica & años) & cuarta era. \\
\hline
\end{tabular}

Como se puede observar, de alguna manera, es en el ámbito de las religiones donde adquieren pleno sentido los cálculos de cuentas largas basados en las periodicidades anuales o de ciclos plurianuales. Excepto las cuentas cristiana y musulmana, que tienen como referente de inicio hechos históricos, las tradiciones judías, mayas e hindús marcan como punto inicial hipotéticas o imaginarias creaciones del mundo. Esto es, el punto de partida es el cero. Según dijimos antes, no como la nada, ex nihilo, de la tradición teológica escolástica, sino como el día que precede al registro del primer día de la cuenta larga. El primer día del registro es, desde este punto de vista, el primer día de la creación: desde donde el registro de la memoria empieza.

Cuando el autor anónimo del artículo“Les deuxzéros mayas”(s/f: 1) pregunta, “¿que sabemos de los diversos comienzos de la historia de la invención del cero históricamente testimoniada en cuatro civilizaciones urbanas situadas en China,

13 Un día de Brahma es un kalpa que consiste en mil ciclos de cuatro eras o yugas. La vida de Brahma duraría aproximadamente 300 billones de años terrestres, al término de los cuales otro Brahma reinicia el ciclo. http://www.tayabeixo.org/historia/his_india.htm 
India, Mesopotamia y Mesoamérica?" La respuesta especulativa posible es que el cero presidió la cuenta de los años.

Antes de su invención que permitió la contabilidad del tiempo del universo, se concibe el cero de historia: esto es, el tiempo transcurrido desde los orígenes de la sociedades neolíticas hasta la invención de la escritura y las series numéricas; aproximadamente unos diez mil años.

Lo que es indudable es que el recuento del tiempo supone como requisito sine qua non, la invención, en primer lugar, del tiempo como hecho total, limitado, por tanto, mesurable, y, en consecuencia, de sistemas numéricos capaces de permitir la medición de apreciables lapsos. O, mejor, de crearlos. Esta forma ordinal no sería posible sin las operaciones que implican las observaciones del transcurso de los ciclos menores de los que se compone el largo periodo que, en ciertos casos, es también un ciclo aunque de mayor magnitud. Nos referimos a los ciclos solares, lunares o venusinos que entrañan distintas magnitudes y, respecto del ciclo mayor, concordancias que se basaron en prolijas observaciones y -¿por qué no?- en cálculos matemáticos.

\subsection{Las etnomatemáticas}

\subsubsection{Las ciencias matemáticas ¿`son etnomatemáticas?}

Esta pregunta surge precisamente para cuestionarnos si la Etnomatemática es una "mirada nueva de la matemática", a decir del profesor Ubiratán D’Ambrosio, integradora de los términos:

ETNO = Ambiente natural, social, cultural e imaginario.

MATEMA = De explicar, aprender, conocer, tratar con.

TICA $=$ Modos, estilos, artes, técnicas

Y, que dentro de esta perspectiva se añade a la matemática occidental, proveniente del flujo europeo, árabe, babilonio y egipcio, como un instrumento de añadidura o corriente necesaria para recobrar los aportes de los pueblos aborígenes americanos.

O tal vez sea necesaria otra pregunta, ¿es la etnomatemática una categoría epistémica de la ciencia matemática?

Esta pregunta surge de la premisa de la universalidad del conocimiento matemático, de la génesis del saber aritmético en el procedimiento de identificar objetos reales mediante una metodología cognitiva del sapiens que logró construir ideas abstractas conocidas posteriormente como números para asociarlas a la presencia de objetos visibles, naturales y numerables.

En este sentido, vale visualizar esas construcciones que evolucionan tras el conocimiento matemático, sobre todo en Europa, que impulsa en la Edad Moderna, a través de ese renacimiento del saber clásico, la constante búsqueda de Fibonacci en los aportes árabes, inventores del álgebra y herederos además del sistema de numeración hindú. La "casualidad” que impulsa a Pascal y Fermat a elaborar una Teoría de la Probabilidad tras la petición del Caballero de la Méré. 
El rumbo que toma esa matemática viene alimentado por los entornos sociales, políticos, económicos y sociológicos de un estadio social en constante cambio. La gravitación universal newtoniana no es casual, surge desde las raíces geocéntricas de Ptolomeo en contraste con la visión heliocéntrica de Copérnico, Kepler y el inolvidable Giordano Bruno, claro está, envueltos también en la oscuridad escolástica y de la nefasta inquisición.

$\mathrm{Y}$ es entonces donde debemos mirar a la matemática como un edificio que se construye en un entorno humano, de comunidad, de contraposiciones de ideas, de intereses económicos y políticos.

Y la etnomatemática toma fuerza como una categoría que debe ser estudiada dentro y fuera de la ciencia matemática, sin crear por ello una dicotomía sino más bien una esencia integradora, multidiversa y con evidentes matices de complementariedad.

El aporte de los saberes matemáticos, sin dejar de ser aporte de los grupos culturales genera a través de sí mismos la condición humana de lo universal. No puede estudiarse un concepto o idea matemática sin mirar su contenido en la línea del tiempo, y más allá del nicho histórico, en las condiciones de la sociedad en su realidad como constructo antropológico y su relación con la naturaleza.

\subsubsection{Sistemas numéricos}

En la sexta parte, titulada "La balanza igual", del tercer volumen, El origen de las maneras de mesa, de Mitológicas, Lévi-Strauss dedica su estudio sobre la mitología americana a las series numéricas de las etnias americanas que revelan los textos de algunos mitos. El método que utiliza para establecer la numerología de cada cultura consiste en:

... de terminar el espíritu de cada sistema sin introducir las categorías del observador, y tener en cuenta la filosofía aritmética que se desprende de las prácticas y las creencias, sin olvidar por otra parte, que ellas pueden estar en acuerdo o desacuerdo o en contradicción con la nomenclatura (1968: 277).

No olvidemos que para Lévi-Strauss las estructuras de los entes matemáticos son puras y exentas de toda referencia que no sea la estricta lógica. De manera que suponen un ejercicio fundamentalmente lógico, lo que, en cierto sentido, contradiría el carácter natural o concreto del pensamiento mito-lógico. Sin embargo, tiene éste tres posibles pretextos a la mano: por una parte los ciclos fisiológicos o duración de la vida humana, tema al que los mitos americanos dedican varios textos, la periodicidad cíclica o los cambios estacionales repetitivos y la larga duración o el tiempo como hecho mesurable.

Respecto de los sistemas numéricos, Lévi-Strauss establece la existencia de sistemas binarios, quinales, decimales y vigesimales. Los primeros, binarios y quinales, predominan entre las poblaciones tribales periféricas a los centros civilizatorios, en tanto que los sistemas de base decimal o vigesimal fueron adoptados por las civilizaciones; la inca en el primer caso, y la maya en el segundo. La búsqueda en los textos míticos de diversas menciones de los sistemas de numeración con- 
duce al autor a encontrar ciertas particularidades que no necesariamente siguen la pauta de los conceptos numéricos que funcionan a manera de operadores de conjuntos. Pues, la naturaleza de significaciones de los sistemas numéricos en los mitos permite que funcionen a manera de operadores de reorganizaciones posibles.

Sin duda el número 10, número cardinal, no define toda la familia de todos los conjuntos de 10 términos concebibles en lo absoluto. Pero define al menos todas las que son concebibles en el universo del mito. Hemos señalado antes esta diferencia entre pensamiento científico y pensamiento mítico: el uno trabaja con conceptos, el otro con significaciones, y si el concepto aparece como el operador de la apertura de un conjunto, la significación parece como el operador de su reorganización (1962: 30).

Un ejemplo de estos sistemas numéricos basados en significaciones es el de los cofán, A'í, que ocupan el segmento alto de las cuencas de los ríos San Miguel Putumayo y Aguarico, en las zonas montañosas del piedemonte andino oriental. En su entorno montañoso hubo vetas auríferas que fueron explotadas tanto en el periodo preinca, inca y el colonial. En el primer caso, intermediaron el oro los pastos y las redes del imperio, en el segundo. El oro, generalmente de aluvión, fue trocado por sal.

Borman (1976) trae un interesante registro en lengua de los A'í. Un breve léxico basado en la raíz, agatto, agattócho, que significa número, es el siguiente: agattocañe (verbo infinitivo): contar; o agatto' ye (medir, contar); agatto en'su (creador, o, uno que pide a otro para contar); agatto'su (contador, medidor). El sistema numérico conoce dos versiones: la de los cofán del Aguarico y la de los del Putumayo-San Miguel. Las variantes no son gratuitas, puesto que permiten reconocer una curiosa secuencia numérica basada en combinaciones sumatorias de un número en base de uno de sus precedentes. Además es una combinación del sistema decimal y vigesimal. Estos aspectos es posible apreciar en la tabla siguiente.

Tabla 4: Sistema numérico de los cofán

\begin{tabular}{|c|c|c|c|}
\hline \multicolumn{2}{|c|}{ NÚMEROS } & \multicolumn{2}{|c|}{ COMBINACIONES SUMATORIAS } \\
\hline fuécco & uno & & \\
\hline \multirow[t]{2}{*}{ ccoangi'cco } & dos & & \\
\hline & & ccoanifue'cco & dos + uno $=$ tres \\
\hline \multirow[t]{2}{*}{ ccattufayi'cco } & cuatro & & \\
\hline & & fuefayi'cco & uno + cuatro $=$ cinco \\
\hline coenchoyi'cco & cinco & & \\
\hline \multirow[t]{3}{*}{ ccáfaiseyi' cco } & seis & & \\
\hline & & ccáfaisecoenchoyi'cco & seis...cinco \\
\hline & & ccáfaise(yi)ccoangi' cco & seis ...dos $=$ siete \\
\hline \multirow[t]{2}{*}{ condaseyi'cco } & siete & & \\
\hline & & ccáfaise(yi)ccoanifue' cco & seis + dos $=$ ocho \\
\hline \multirow[t]{2}{*}{ entingyi'cco } & ocho & & \\
\hline & & ccáfaise(yi)ccattufayi'cco & seis ...टं? cuatro = nueve \\
\hline utufayi' cco & nueve & & \\
\hline tivepa'tssi & diez & & \\
\hline & & tsu'ttepipa'tssi & Veinte \\
\hline
\end{tabular}


Sorprende la complejidad de las operaciones que supone este sistema numérico. Más aún si se considera que éstas ocurren como variantes de segmentos tribales separados y aislados por espacio de un siglo y ochenta y más años de vida republicana.

Otras sorpresas depara el sistema numérico decimal en sus expresiones de organización. Lévi-Strauss propone como ejemplo la alineación de los clanes aves-trueno y serpientes: para encontrar una forma de evitar el estancamiento del flujo de la secuencia de periodicidades, los unos no se enfrentan a los otros sino que asumen una figura espiral que posibilita un ordenamiento de las secuencias en grupos quinales. Esta curiosa disposición de dos series decimales en un ordenamiento de cuatro series quinales se muestra en el gráfico que reproduce el autor en el segundo volumen de mitológicas:

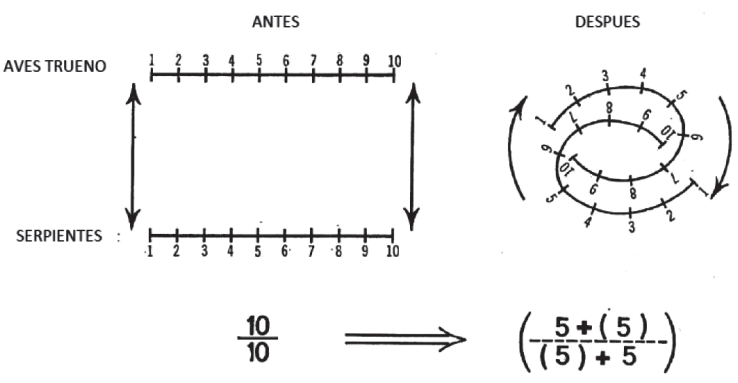

Periodicidad estacional (1968: 297)

Otras construcciones de los mitos suponen la combinatoria de secuencias numéricas cardinales y ordinales. Este es el caso del mito Menomini del mito del sol entrampado y el ciclo de las décadas, cuyo recuento lo debemos a Lévi-Strauss. Éste puede ser expuesto en los términos siguientes:

a) tres hermanos cazadores disponen de dos itinerarios: uno se dirige a la derecha y el otro la izquierda;

b) el primer día los dos hermanos mayores toman el camino de la derecha: encuentran un oso que mata el mayor; el tercer hermano no encuentra nada;

c) el segundo día, los mayores que siguen por el mismo camino encuentran un oso que mata el segundo de los hermanos mayores; el menor, por el otro camino, mata uno;

d) el tercer día, cada hermano mata un oso en el cruce de los caminos: primero el menor, luego los dos mayores; y, finalmente, los tres actuando de conjunto; sin embargo, cada vez, su padre se queja que cada día no hay un oso de más.

La serie de números formales y virtuales es la que sigue:

I, [1(+1)]; II, [2(+1)]; III, [3(+1)].

Esta serie yuxtapuesta al orden en que los osos fueron cazados por los hermanos resulta en la construcción ordinal siguiente:

$\left(1^{\circ}, 0,0\right),\left(0,2^{\circ}, 3^{\circ}\right),\left[\left(3^{\circ}\right),\left(2^{\circ}, 1^{\circ}\right),\left(3^{\circ}, 2^{\circ}, 1^{\circ}\right)\right]$. 
La explicación posible de esta curiosa construcción la encuentra el autor en el hecho que "La repartición variable de los hermanos por las dos rutas añade una coordenada geométrica a las dos precedentes cuya naturaleza es aritmética, pero que aluden, la una al número cardinal, la otra al número ordinal" (1968: 323).

Como se puede apreciar, si hay algún interés en indagar acerca de las series numéricas es imprescindible asumir como punto de partida los textos de las narraciones míticas antes que orientar las investigaciones a un recuento simple de los nombres atribuidos a las series. Y, como consecuencia del método estructural, parce recomendable atender a las cualidades y propiedades de plantas y animales del entono.

\subsubsection{Construcciones matemáticas}

La revolución neolítica en el contexto americano se basó en el desarrollo de un apreciable conjunto de conocimientos a los que, según las categorías propuestas por Lévi-Strauss podemos agrupar en: a) conocimientos empíricos relativos al entorno natural; b) conocimientos aplicados a las estructuras sociales; c) sistemas numéricos y aritméticos aplicados a las periodicidades estacionales y calendáricas; y d) formas geométricas aplicadas a la sintaxis de los mitos. En este acápite revisaremos algunas de sus implicaciones epistemológicas.

\section{a) Conocimientos empíricos relativos al entorno natural}

Un aporte atribuible a los antropólogos es la certeza que en las sociedades dichas primitivas o en determinados segmentos de las sociedades civilizadas hay un conjunto de saberes empíricos que, en sentido estricto, no son compatibles con la ciencia, aunque constituyen notables aportes desde el punto de vista de los conocimientos que han logrado sistematizar utilizando categorías basadas en la percepción de las cualidades y formas, de la manera como se han establecido categorías que utilizan las ciencias empíricas como la botánica o la zoología.

A estos conocimientos, unos los categorizan como saberes. Esto es, no sistematizados como los conocimientos científicos. Otros les atribuyen la categoría de ciencias, basados en el argumento de que se trata de conocimientos sistemáticos que utilizan otras categorías. En todo caso, las propuestas de las etnociencias no son nuevas. Emergen hacia los años 80 del siglo anterior. De manera que a lo largo de tres o cuatro décadas algunas alcanzaron una autonomía relativa como ámbitos disciplinarios. A fin de ilustrar este proceso mencionamos cuatro casos: la etnohistoria, la etnobotánica, los conocimientos agronómicos y lo que se conoce como arqueoastronomía que no es lo mismo que la astroarqueología.

Lévi-Strauss destaca la magnitud de los conocimientos botánicos al mencionar que los Hanunóo de Filipinas utilizan la flora local en una proporción de un 95\% (Conklin: citado por Lévi-Strauss: 1964: 15). Y, respecto a las categorías de la fauna, reproduce los registros de Conklin:

En total llevan un censo de 461 clases zoológicas. Los Hanunóo clasifican las formas locales de fauna aviar en 75 categorías ... distinguen cerca de 12 clases de serpientes ... sesenta clases de peces ...más de una docena de crustáceos de mar y 
de agua dulce, y un número igual de arañas y miriápodos ... Los miles de formas de insectos se agrupan en ciento ocho categorías que tienen nombre, trece de las cuales corresponden a las hormigas y termitas ...Identifican más de sesenta clases de moluscos marinos, y más de veinticinco de moluscos terrestres ...cuatro clases de sanguijuelas chupadoras de sangre.

La idea es que se trata de conjuntos de conocimientos acumulados y sistematizados por diversas etnias o segmentos de diferentes sociedades, en base de interacciones con su entorno. Su sistematización implica el uso de categorías, distintas, ciertamente, de las usuales en las ciencias, y, a diferencia de éstas, se trata de categorías lógicas que emergen de las cualidades y formas percibidas desde la realidad sensible.

A diferencia de la ciencia y la filosofía occidentales que establecen criterios clasificatorios sustentados en categorías que se asume son construcciones mentales, las etnociencias asignan a los discursos de los mitos, en los que se expresan, la lógica de las cualidades y de las formas. Como plantea Lévi Strauss en el tercer volumen de sus Mitológicas, L' origine des manières de table, “...la lógica de las cualidades y la lógica de las formas, que hemos distinguido desde un punto de vista teórico, pertenecen de hecho a los mismos mitos..." (1968: 407).

\section{b) Conocimientos aplicados a las estructuras sociales}

Las prescripciones y prohibiciones matrimoniales que Lévi-Strauss las concibe como fundamento de las alianzas matrimoniales se originaron con la revolución neolítica. En cierto sentido, el orden social que impone la prohibición del incesto nació con las sociedades sedentarias. Los modelos de sociedades que se constituyen en base de los grupos exógamos que intercambian mujeres van desde las formas duales, visibles, por ejemplo en las sociedades andinas, algunas de las cuales han evolucionado a formas tripartitas y otras, por subdivisiones de los grupos binarios, presentan modalidades organizadas en cuatro grupos. Acerca de las sociedades organizadas en grupos binarios afirma lo siguiente:

...las organizaciones dualistas presentan muchos rasgos en común: la descendencia es, por lo general, matrilineal; dos héroes culturales, a veces hermanos mayor y menor, a veces gemelos, desempeñan un papel importante en la mitología; a la bipartición del grupo social sigue, con frecuencia, una bipartición de los seres y de las cosas del universo y las mitades están asociadas con oposiciones de características: lo Rojo y lo Blanco; lo Rojo y lo Negro; lo Claro y lo Sombrío; el Día y la Noche; el Invierno y el Verano; el Norte y el Sur; el Este y el Oeste; el Cielo y la Tierra; la Tierra Firme y el Mar o el Agua; lo Izquierdo y lo Derecho; lo Bajo y lo Alto; lo Superior y lo Inferior; lo Bueno y lo Malo; lo Fuerte y lo Débil; el Mayor y el Menor. Junto con las organizaciones dualistas, a veces se encuentra una dicotomía del poder entre un jefe civil y un jefe religioso o entre un jefe civil y un jefe militar. Por fin, las mitades están unidas una con otra, no sólo por los intercambios de mujeres sino por el abastecimiento de prestaciones y contraprestaciones recíprocas de carácter económico, social y ceremonial (1969: 109).

El análisis antropológico de estos modelos implica el recurso de las matemáticas. La teoría de las probabilidades en los sistemas cuadripartitos supone las com- 
binaciones de A, B, C y D como entes que, a la vez entregan y reciben esposas. La norma que prima en estos modelos duales es la del matrimonio preferencial de primos cruzados, tratándose de la hija del hermano de la madre. Las variantes de los modelos resultantes dependen de las reglas de filiación, descendencia y los usos residenciales.

Esta organización dual tiende a volverse compleja a medida que el autor incursiona en los sistemas de intercambios restrictivos (sistema murgin) e incluso en las formas simples del intercambio generalizado. La explicación que plantea el autor en Las estructuras eelementales de parentesco (Lévi-Strauss: 228, cita a S. M. Shirokogoroff, The psychomental complex of the tungus, pág. 104.) es que "Los fenómenos sociales pueden existir y operar, sin ser objetos de conocimiento".

\title{
c) Sistemas numéricos y aritméticos aplicados a las periodici- dades estacionales y calendáricas
}

La agricultura, ampliamente difundida a partir de la revolución del neolítico implicó la sistematización de secuencias o periodicidades estacionales. En muchos casos, puesto que la agricultura se combinaba con el uso de recursos del entorno (pesca, caza, recolección), supuso, a la vez, un reconocimiento exhaustivo y sistemático del entorno.

Los calendarios lunares y solares y las sucesiones estacionales suponen el recurso de observaciones empíricas y mediciones. La construcción de calendarios solares, lunares y el venusino suponen cálculos de órbitas: estelar (sol), satelital (luna) y planetaria (Venus). Los mayas incluyeron cálculos más sofisticados, según el Calendario del Instituto de Astronomía (UNAM: 2012),

\begin{abstract}
Los mayas determinaron el inicio y el término de sus periodos calendáricos. En los cálculos de fechas de su interés incluyeron eventos planetarios periódicos como una forma de validar sucesos sociales o religiosos importantes para su cultura. Estos eventos astronómicos involucraban ciclos lunares y solares de corto plazo, ciclos de Venus en múltiplos de ocho años, y también grandes ciclos de cientos y miles de años a través de combinaciones de ciclos de Mercurio, Venus, Marte, Júpiter Saturno y la Luna.
\end{abstract}

En la Tabla 5 constan los ciclos o periodicidades del calendario Maya conocido como de cuenta larga; esto es, de los 1'871.645 días transcurridos desde el 11 de agosto del 3.114 a.C., cuando inicia la cuenta, hasta el 01 de enero de 2012 (12.19.19.0.5; esto es, 12 baktun, 19 katun, 19 tun, 0 uinal. 5 kin).

Tabla 5: Ciclos, secuencias, duración y lapsos de la cuenta

\begin{tabular}{|l|l|l|l|}
\hline Ciclos & Secuencias & Duración & Lapsos \\
\hline 1 KIN & $(0.0 .0 .0 .1)$ & 1 día & 1 día \\
\hline 1 UINAL & $(0.0 .0 .1 .0)$ & 20 días & 20 días \\
\hline 1 TUN & $(0.0 .1 .0 .0)$ & 18 UINALES & 360 días \\
\hline 1 KATUN & $(0.1 .0 .0 .0)$ & 20 TUNES & 7.200 días \\
\hline 1 BAKTUN & $(1.0 .0 .0 .0)$. & 20 KATUNES & 144.000 días \\
\hline
\end{tabular}

Fuente: Calendario Instituto de Astronomía, UNAM, 2012 
El tiempo cíclico aparece registrado en un calendario tecnoeconómico y ritual, el Haab, compuesto por ciclos de 18 meses de 20 días y un mes adicional de cinco días, UAYEB, dedicado a los ritos agrarios. Y el tiempo sagrado fue registrado en un calendario religioso, Cholq'ij, que comprendía ciclos de 260 días, según una secuencia iterada de 13 ciclos de 20 días cada uno. Como plantea Lévi-Strauss (1968:335):

La perspectiva histórica se origina en la gradación progresiva de conjuntos de 12 días, 12 meses, 12 años, 12 decenas, 12 siglos... deriva de una fórmula todavía estática: de la esperanza de un futuro histórico, en tanto que los Indios, que no admiten otros eventos que aquellos que los mantienen en el tiempo agitado de los mitos, prefieren la fórmula repetitiva de la periodicidad que les prevenga contra toda incursión del futuro.

\section{d) Formas geométricas aplicadas a la sintaxis de los mitos}

El proceso de invención de los mitos a partir de una versión originaria puede ser comprendido como un proceso que por simetrías y desigualdades culmina en construcciones cuya lógica es traducible en términos algebraicos y geométricos. De hecho, Lévi-Strauss en los cuatro volúmenes de Mitológicas y en sus ulteriores publicaciones despliega un espectacular muestrario de estructuras sintácticas de mitemas. Según el autor que comentamos:

Todos nuestros análisis demuestran -y es la justificación de su monotonía y su número- que los alejamientos diferenciales reiterados por los mitos no radican tanto en las mismas cosas como en un conjunto de propiedades comunes o expresables en términos geométricos y transformables unos en otros por medio de operaciones que constituyen un álgebra (1964: 407).

La topología y su comprensión matemática es la forma en la que se produce esa mancomunidad de cualidades y propiedades de la naturaleza y las interpretaciones del pensamiento. A tal punto son construcciones complejas que creativos diagramas son utilizados como recurso para ilustrar algunas de las "frases" simbólicas.

Cabe preguntar si dadas las diferenciaciones culturales que es posible encontrar en el espacio del Continente Americano es dable detectar una posible trayectoria de la evolución del pensamiento mito-lógico, de la misma manera como ha sido posible trazar la evolución del pensamiento filosófico, o, incluso de las ciencias, o de las matemáticas. $\mathrm{Al}$ respecto, Lévi-Strauss sugiere que los mitos no forman parte de un sistema acabado. En cierto sentido, su estudio de los mitos americanos no es sino, un estudio de "anatomía comparada" de varias especies míticas que son del mismo género. Y concluye reiterando su pregunta: ¿cómo y en qué orden cada una adquirió su originalidad? (1968: 216). 


\section{Conclusiones}

"El gran libro de la naturaleza está escrito en símbolos matemáticos" Galileo (1564-1642)

¿Es el pensamiento mito-lógico el fundamento de las etnomatemáticas? O, de manera general, ¿de las etnociencias?

La clave para formular una respuesta la adelantamos en el acápite preliminar: lo que parece estar en la mesa del debate no es el hecho de que las construcciones lógicas que descubren las investigaciones en etnomatemáticas sean, o puedan ser, comparables con las de las ciencias matemáticas. Y, parece evidente el hecho que los sistemas numéricos y las construcciones probabilísticas, lo mismo que el álgebra de las estructuras de los mitemas son visibles, en gran medida, a partir de las matemáticas. De manera que, si debido a la evolución de las ciencias a lo largo de los siglos XVI-XIX no fue posible visualizar estos avances, en la actualidad lo es a causa del desarrollo de las matemáticas binarias o de la geometría fractal o de los números p-ádicos.

La geometría fractal de Mandelbrot es la propuesta matemática contemporánea que mejor ilustra el planteamiento de Lévi-Strauss: las formas geométricas y sus propiedades corresponden a fenómenos u objetos de la naturaleza; su visualización y formalización es el aporte de las ciencias matemáticas. Como plantea el autor, más allá de los símbolos numéricos o fonemas o mitemas hay un pensamiento natural o simbólico cuyo valor radica en el vínculo indisoluble con la naturaleza. No es a partir de las construcciones abstractas que es posible comprender la naturaleza sino son las cualidades y formas de la naturaleza las que sustentan las diversas construcciones matemáticas o etnomatemáticas.

Como corolario de estas breves reflexiones, podemos establecer el sentido en el que parece legítimo hablar de etnociencias o etnomatemáticas. Si se examina los ámbitos a los que aluden el prefijo griego ethnos, pueblos: por una parte, la etnografía, definida como la descripción del modo de vida de un pueblo, y por otra, la etnología, definida como el conjunto de reflexiones sobre aspectos comparativos del modo de vida de varios pueblos, es posible establecer que las etnociencias / etnomatemáticas no son sino ámbitos específicos de las dos disciplinas: tanto como descripción de los sistemas numéricos como de sus implicaciones en cuanto construcciones lógico-matemáticas.

Hay otro sentido, el que postula D'Ambrosio, que alude al valor actual de tales prácticas, frente a las ciencias matemáticas, y, en consecuencia, a su pervivencia como sistemas no formales. Estos son, a su vez, argumentos que permiten plantear el rescate de tales conocimientos o saberes para facilitar la enseñanza de las matemáticas en contextos pluriculturales. De manera que no es el valor intrínseco por el que algunos investigadores han asumido investigaciones que las categorizan bajo este ámbito. Es su valor en cuanto constituyen vehículos de enseñanza /aprendizaje, proponer innovadores horizontes para propiciar una convergencia de saberes o atribuir su importancia a la construcción de la interculturalidad. No como un espacio abstracto y neutro sino como conviene a la propuesta de la era del conocimiento. 
Y hay un tercer sentido que adquiere plena validez como soporte de los anteriores. Se trata del protagonismo que en el ámbito de las etnociencias compete a las sociedades a las que corresponden los conocimientos a los que hemos categorizado como parte de las etnociencias. Tema problemático, por varias consideraciones; sobre todo, el hecho de que estas sociedades, desde al menos tres o cuatro generaciones, se encuentran inscritas en el sistema de aprendizaje de los conocimientos de las ciencias lo que supuso el abandono parcial, y a veces total, de sus conocimientos.

La solución posible podemos encontrarla en el diseño de un conjunto de interacciones entre ciencias y etnociencias. El horizonte epistemológico propuesto por Lévi-Strauss desde la perspectiva de los mitemas y sus implicaciones en términos de construcciones algebraicas o geométricas logradas a partir de las combinaciones posibles del lenguaje simbólico, ocupa una posición definida en la evolución de las ciencias: al término de una coyuntura marcada por la crisis de la metafísica, con Russell, Whitehead y Wittgenstein, tuvo como antecedentes otras propuestas imaginadas por Leibniz, Spinosa y Boole. Sin contar con la semiología que Saussure, acaso sin saberlo, postuló como el puente oportuno para concebir la universalidad del pensamiento simbólico; no sólo en el lenguaje que expresa el razonamiento abstracto sino de toda manifestación cultural.

Si los razonamientos abstractos pueden ser reducidos a un conjunto de proposiciones lógicas, ¿sucedería algo similar a lo que ocurre cuando los "razonamientos" de los mitos, que reducidos a un conjunto de proposiciones lógicas, permiten construcciones geométricas y algebraicas?

Entonces debemos admitir que entre el razonamiento abstracto y el mito-lógico hay una traducción posible y ésta es la lógica simbólica. Debemos admitir, además, que entre el lenguaje construido por semantemas y el de las matemáticas, construido por los símbolos numéricos, hay afinidades evidentes, al igual que entre el lenguaje de glifos de los mayas y los símbolos numéricos hasta ahora revelados.

Más allá de las posibles traducciones que puede ofertar la semiología se encuentra el tema de la estructura de la mente humana. ¿Tiene coherencia la propuesta de Lévi-Strauss cuyo antecedente más próximo lo encontramos en Boole? Recordemos que para el matemático, la estructuración de una lógica matemática revela que lo importante es el estudio de "...las leyes fundamentales de las operaciones de la mente en cuya virtud se realiza el razonamiento". El tema lo plantea Lévi-Strauss aunque su explicación no la resuelve sino de manera tangencial cuando compara los discursos míticos que perviven en la contemporánea civilización global, o sus expresiones en representaciones rituales que muestran rasgos comunes de diversas religiones o, digámoslo así, en las notorias convergencias de las investigaciones científicas y los saberes tecnoeconómicos de sociedades periféricas. A medida que se profundiza la materia propuesta al estudio lingüístico, se convence cada vez más de esta verdad que, será inútil disimular, es materia de reflexión: 'que el vínculo que se establece entre las cosas preexiste en ese ámbito, a las cosas mismas, y sirve para determinarlas' (1968: 215-216). 
En cuanto a lo primero, el devenir generacional es pensado a partir de las reglas matrimoniales. La renovación de la sociedad es pensada como una iteración de los modelos de intercambios que tienden a reproducirla ilimitadamente. Se intercalan en la sucesión generacional diversos ritos de pasaje, nacimientos, matrimonios o defunciones, a los que distintas sociedades prestan mayor o menor atención.

No es el caso de los periodos estacionales. Estos están relacionados con los ámbitos tecnoeconómicos, distintos para el hombre y la mujer, y con la astronomía. Y, en ciertos casos, con los entornos zodiacales y zooemas que anuncian la transición de una a otra estación. Este es el origen de los calendarios y su inevitable consecuencia, la medición de un periodo anual que no siempre es una serie iterada de doce meses. Se trata de "...un sistema inteligible en la sincronía” y no de simples trazas de evolución diacrónica (1968: 57).

En las construcciones de las periodicidades temporales, el futuro, según Lévi-Strauss, es un tema vedado en las sociedades del pensamiento mito-lógico. Se presenta como un tema característico de aquellas sociedades a las que se puede considerar como históricas: no, por supuesto, en el sentido temporal sino en cuanto se representan a sí mismas proyectadas hacia el futuro. Nos preguntamos si es éste el caso de los mayas que en su concepción de un tiempo absoluto, la cuenta larga, y en los cíclicos, el secular, relacionado con la agricultura, tema vital, y el religioso, estrechamente vinculado al conocimiento de las secuencias calendáricas.

¿Fue éste el procedimiento que emplearon los mayas para calcular la órbita de Venus y construir el calendario venusino con asombrosa precisión?

Desde el punto de vista epistemológico, un hecho parece incontestable: las etnomatemáticas son posibles a partir de las ciencias matemáticas y la filosofía. La Europa del descubrimiento de América estaba dominada por el pensamiento filosófico tomista al igual que el desarrollo de las matemáticas. La filosofía tomista fue heredada de la griega, preservada por los árabes, y apenas había iniciado algunos notorios avances a causa de la incorporación del cero en el sistema numérico y, sobre todo, en la astronomía impulsada por la rápida evolución de la navegación marítima a larga distancia.

\section{Bibliografía}

Acosta, José de (1590), (1979). Historia natural y moral de las Indias. México: FCE.

Anón. Les deuxzéros mayas. S/f; s/l.

Aráuz, Julio (2012). Orígenes ecuatorianos: más allá de la Tolita. Quito: Universidad Internacional del Ecuador, UIDE.

Bell, E. T. (...). Los grandes matemáticos (desde Zenón a Poincaré). Su vida y sus obras. Buenos Aires: Losada.

Bestard, J. \& Contreras, J. (1987). Bárbaros, salvajes y primitivos. Barcelona: Barcanova.

Borman, M. B. (1976). Vocabulario cofán. Quito: ILV-Ministerio de Educación Pública.

Eido Tai Shimano \& Kogetsu Tani Roshi (1990). Zengo \& Bokuseki. New York. 
Eribon, Didier \& Lévi-Strauss, Claude (1988), (1990). De cerca y de lejos. Madrid: Alianza Editorial.

García, Gregorio (1607), (1981). Origen de los indios del Nuevo Mundo. México: FCE.

Guerrero, Marcos (2004). Los dos máximos sistemas del mundo. Quito: AbyaYala.

Marsh, Peter. Polynesian Pathways, http://users.on.net7-mkfenn/index.html, created October 2002.

Morales Aldana, L. (2004). La cuenta larga del calendario maya y su notación. Revista Brasileira de História da Matemática - vol. 4. no 7 (abril/2004 - setembro/2004) - pág. 69 78. Publicação Oficial da Sociedade Brasileira de História da Matemática.

Kuhn Thomas S. (1971). La estructura de las revoluciones científicas. México: FCE (primera edición en español).

Lévi-Strauss, Claude (1962), (1964; 1997). El pensamiento salvaje. Bogotá: FCE Ltda.

- (1964), (1968). Lo crudo y lo cocido. México: FCE.

— (1966), (1971). De la miel a las cenizas. México: FCE.

- (1968). El origen de las maneras de mesa.

- (1969). Las estructuras elementales de parentesco. Barcelona: Paidós Ibérica.

— (1958; 1974), (1987). Antropología estructural. Barcelona: Paidós

— (1971), (1991). El hombre desnudo. México: Siglo XXI

— (1985), (1986). La alfarera celosa. Barcelona: Paidós Ibérica.

— (1999). Raza y cultura. Madrid: Altaya. http:/pedagógica. Blogspot.com.

Propp, Vladimir (1928). Morfología del cuento.

(1983). El epos heroico ruso. (2 vols) Madrid: Fundamentos.

Miarka, Roger (2011). Etnomatemática: do ônticoao ontológico. Tese de Doutorado presentada ao Instituto de Geociências e Ciências Exatas do Câmpus de Rio Claro, da Universidade Estadual Paulista Júlio de Mesquita Filho, Río Claro.

Russell \& Whitehead (1910 -13). Principia mathematica.

Saussure, F. de (1916). Cours de linguistique générale, París [trad. cast.: Curso de lingüística general, Barcelona, Akal, 1981].

Wittgenstein, Ludwig (1923). Tractatus lógico philosophicus. 


\section{ENSEÑANZA DE LA FÍSICA EXPERIMENTAL EN LA EDUCACIÓN SUPERIOR DESDE UNA PERSPECTIVA CRITICA. CASO: ESTUDIANTES UCE}

Guillermo Terán Acosta

Universidad Central del Ecuador. Unidad de Física

Recibido: 16 - noviembre - 2015, aprobado 18 - diciembre - 2015

\section{Resumen}

El presente estudio tiene como propósito fundamental generar un cuerpo estable de ideas sobre estrategias innovadoras en la enseñanza y aprendizaje de la Física Experimental en la educación superior, desde una perspectiva crítica. Un estudio de caso: Estudiantes de la Universidad Central del Ecuador (UCE). Con la finalidad de lograr el propósito planteado, se procedió a caracterizar la situación actual, analizando factores y variables sobre rendimiento, aprendizaje, actitudes y evaluación de los aprendizajes del trabajo experimental que los estudiantes realizan en los laboratorios de Física, para lograr una visión diagnóstica. Sobre la base de dicha información se pretende que la universidad pueda desarrollar cambios profundos en su quehacer académico en esta área del saber -con visión multidimensional y sinérgica- para reformularla, fundamentados teóricamente en el aprendizaje de la Física Experimental como investigación conducente a la construcción de nuevos conocimientos en el contexto de la resolución de problemas abiertos (Gil. D). La metodología, desde el punto de vista filosófico, se apoyó en lineamientos inherentes a una investigación multireferencial, multidimensional e interpretativa, que incluye una investigación de campo y documental-bibliográfica de tipo cuasi-experimental de carácter descriptivo y correlacional. Según la perspectiva cuantitativa, se aplicaron instrumentos de escala aditiva -conocida como de tipo Likert- a una muestra de 366 estudiantes. Desde la perspectiva cualitativa se realizaron entrevistas en profundidad a informantes clave. Se complementa el análisis de resultados y procesos, construyendo flujos teoréticos contrastados con los observados -triangulación-. Sobre la base de los hallazgos se estructuró un conjunto de reflexiones que poseen la probabilidad de sugerir la implementación de estrategias alternativas de enseñanza, apoyadas en concepciones filosófico-epistemológicas, científicas y humanísticas, tendientes a elevar las competencias investigativas de los estudiantes en la Física Experimental.

Palabras clave: enseñanza, física experimental investigativa, resolución de problemas, epistemología, estrategias, educación superior. 